\title{
Systematic kinetic study of magnesium production using magnesium oxide and carbonic materials at different temperatures
}

\author{
Hamid Zahedi ${ }^{1 *}$ (D, Nahid Farzi ${ }^{2}$ and Nasser Golestani ${ }^{3}$
}

\author{
* Correspondence: \\ germanium_110@yahoo.de \\ 'Department of Physical Chemistry, \\ Faculty of Chemistry, Ferdowsi \\ University of Mashhad, Mashhad, \\ Iran \\ Full list of author information is \\ available at the end of the article
}

\begin{abstract}
The main goal of this study was to determine the industrially best reductant for reduction of magnesium oxide to magnesium with wood charcoal and petroleum coke (petcoke) each in molar ratio 1:1 and 1:2 (oxidant:reductant) at high temperatures. In this study, a new and reliable combination of mathematical modeling and discrete numerical optimization theory by presenting 18 "mathematical filters" not relying only on statistical quantities of fitting (contrary to many similar researches) was introduced. The purpose of these filters was the determination of correct kinetic equation and therefore, the corresponding rate coefficient from among 18 equations most used at present in the challenging field of solid state chemical kinetics. With assistance of a new and fundamental mathematical function and the obtained values of rate coefficients, the function of rate coefficient in temperature was attained. The activation energy was then calculated as a function of temperature using the general definition of activation energy and the determined function for rate coefficient. The comparison between different reducing agents in the different conditions and with relevant previous study was accomplished to determine the best reducing agent from industry standpoint. Also, the areas under experimental data were calculated numerically and utilized for method validation and comparison. It turned out finally that relying only on fitting quantities in the solid state chemical kinetics can readily lead to wrong conclusions about the correct kinetic equation and about the most suitable reducing agent. It is obvious that the erroneous calculations and wrong decisions in the laboratory scale become significant and paramount in industry and this reveals the significance of rigorous mathematical analysis.
\end{abstract}

Keywords: Solid State Chemical Kinetics, Mathematical Modeling, Optimization Theory, Correct Kinetic Equation, Magnesium Oxide, Reduction (c) The Author(s). 2021 Open Access This article is licensed under a Creative Commons Attribution 4.0 International License, which permits use, sharing, adaptation, distribution and reproduction in any medium or format, as long as you give appropriate credit to the original author(s) and the source, provide a link to the Creative Commons licence, and indicate if changes were made. The images or other third party material in this article are included in the article's Creative Commons licence, unless indicated otherwise in a credit line to the material. If material is not included in the article's Creative Commons licence and your intended use is not permitted by statutory regulation or exceeds the permitted use, you will need to obtain permission directly from the copyright holder. To view a copy of this licence, visit http://creativecommons.org/licenses/by/4.0/. The Creative Commons Public Domain Dedication waiver (http://creativecommons.org/publicdomain/zero/1.0/) applies to the data made available in this article, unless otherwise stated in a credit line to the data. 


\section{Introduction}

The magnesium $(\mathrm{Mg})$ element is one of metals in our universe with some interesting properties [1]. One significant feature of magnesium is the ability of it to produce much energy in combustion reaction. The considerable point in burning reaction of magnesium is that it does not produce carbon dioxide, a greenhouse gas. Therefore, it is clear that more attention to this metal can solve some fundamental problems of a society. If magnesium is produced through a clean route, such as using renewable energies, the process will be even "greener". In fact, because of many problems such as greenhouse effect resulting from fossil fuels and also, the decrease of these fuels in the future, a striking endeavor has started for producing clean energies from renewable resources [2-7]. In general, renewable energies are of different types and some of them are solar energy, wind energy, tidal energy, geothermal energy, and biomass energy, for example. Among various types of renewable energies, solar energy is an attractive subject for many researchers. It can be said that the human being noticed the importance of solar energy a little late but nonetheless, the subject of solar energy has seen a substantial amount of research projects in various fields [8-17]. It is obvious that the combination of magnesium production and utilizing renewable energies can be very beneficial for human being in this era.

In parallel, the clean and cheap fuels have been always like dreams for all people and especially for scientists, engineers and even, governors. One of the useful and suitable fuels is the hydrogen gas [18]. Therefore, the combination of solar energy and hydrogen production is of fundamental importance for improving industrial processes in order to deal with many difficulties and problems in a society. One of the substances suitable for production of hydrogen is metallic magnesium. Hence, the production of this metal from magnesium oxide $(\mathrm{MgO})$ can be an interesting goal for research and development. Because of high temperatures needed for cleavage of stiff bonds in the crystal of $\mathrm{MgO}$, a carbon-based reducing agent like carbon itself or methane is usually necessary. Therefore, the high energy stored in the concentrated solar radiation and the chemical energy in the carbon-based material can cooperate to overcome the powerful structure of $\mathrm{MgO}$ and to release magnesium in the pure metallic form. The metal produced can create hydrogen gas readily through reaction with water vapor and the hydrogen gas released can be used in the fuel cells for production of electric power. It must be noted that the reaction of magnesium with water vapor is very fast and therefore, this reaction must be performed in a controlled manner and with considering all safety issues.

Additionally, the usage of magnesium itself as a direct fuel has been suggested [1921]. This novel idea is supported from two viewpoints: first, the heat of oxidation of magnesium is about ten times that of hydrogen and second, magnesium available in the seawater is enough for 300,000 years of humankind [19]. The direct usage of magnesium can be made in two modes, reaction with oxygen or reaction with water vapor. When metallic magnesium is mixed with oxygen or water vapor, it produces heat that can be used as a source of energy. The reaction of magnesium with water vapor has the benefit of producing hydrogen gas which can be used to provide energy and the magnesium oxide produced can then be converted back into magnesium using, for example, the solar laser and this forms a useful cycle [19]; the water vapor produced from reaction of hydrogen with oxygen in a fuel cell can be used in this cycle, too. All these studies as well as other fascinating properties of magnesium such as low weight (interesting 
for automobile and aerospace industries) and many others [22] prophesy about the important role that this metallic element will play in the future of our world. These facts reveal the high potentiality of such interesting fields and the importance and usefulness of research in them. Since chemical thermodynamics and chemical kinetics are the fundamental sciences in exploring chemical processes, it is a logical task to study the chemical reactions occurred in these fields thermodynamically and kinetically.

One of the useful studies carried out on magnesium oxide is the work of Gálvez et al. [23] in which the role of $\mathrm{MgO}$ in a solar thermochemical cycle was investigated both thermodynamically and kinetically. Also, Rongti et al. [24] explored the reaction of $\mathrm{MgO}$ with graphite powder kinetically.

The purpose of present paper is to perform a mathematical treatment of some significant but untreated points in the study of Gálvez et al. [23] and perhaps many others, more rigorously from standpoints of chemical kinetics (Chemistry) and optimization theory (Mathematics) coupled to each other in a large extent; this coupling, for first time, approaches the problem thoroughly with not relying only on curve-fitting quantities and therefore, it requires more consideration for understanding it.

\section{Methods}

\section{Theoretical treatment in solid state chemical kinetics (SSCK)}

The reactants in the solid state do not have the ability of moving through matter and therefore, the concentration concept is undefined for them. Even if a diffusion process controls the mechanism of reaction, this diffusion is slow in the solid state. For example, the surface of reaction can goes through body of matter while the reactants are in front and products in behind. As a result, it can be possible to substitute the concentration concept with fraction-of-reaction quantity [25]. The suggested mechanisms in SSCK are very diverse. The nucleation is a typical mechanism while another important one is the diffusion in one or several directions. Totally, there are more than 29 important equations in SSCK which come from different theories [26].

Irrespective of large number of equations presented, it is sometimes possible to fit satisfactorily the experimental data with more than one kinetic equation. Generally, finding correct kinetic equation and in other words the real mechanism had been one of the most difficult tasks in SSCK. From equations suggested, 18 mathematical equations derived from previous scientific researches and represented in Table A1 in Appendix A in Online Resource (Supplementary Material) are used more than others [25-27]. For simplicity, the abbreviations suggested by Sharp et al. [28] were used in Table A1 and throughout this study.

Because of the nature of reactions in the solid state, the considerable amounts for fraction of reaction can be attained only at high temperatures and hence, the temperature can be considered as a powerful catalyst; this is rooted in the very high activation energies involved in SSCK, originated in turn from lack of collisions in the solid state.

\section{Mathematical modeling and raw kinetic data}

The inviolable science of Mathematics is the inseparable part of natural sciences and specially, the fundamental and strategic science of Chemistry named as Central Science 
[29]. Like many cases in chemical kinetics, the starting point is the respective differential equation:

$$
\frac{d a}{d t}=k f(a) \quad, \quad a=a(t)=1-\frac{m(t)}{m(0)}=1-\frac{n(t)}{n(0)}
$$

Before determination of quantities in Eq. (1), it should be said that according to the study of Gálvez et al. [23], in first step of a solar thermochemical cycle, $\mathrm{MgO}$ is reduced to $\mathrm{Mg}$ with assistance of carbonic reducing agent (charcoal or petcoke) and thermal energy from solar radiation and in second step, $\mathrm{Mg}$ is converted back to $\mathrm{MgO}$ through reaction with water vapor and the hydrogen gas is produced as the desired product in Ref. [23]; the focus of our study was on the first step of this solar thermochemical cycle (Eq. (10)). In Eq. (1), $a(t)$ is the fraction of reduction reaction of $\mathrm{MgO}$ to $\mathrm{Mg}$ proceeded in time $t$ and is dimensionless, $k$ is the rate coefficient with dimension of time ${ }^{-1}, f(a)$ is a mathematical function taken from Table A1 and without dimension, $m(t)$ is the remaining mass of magnesium oxide in time $t$ and $n(t)$, the number of moles of remaining magnesium oxide in time $t$. The numerical values of $a$ have been obtained by TGA (thermogravimetric analysis) instrument (TG, Netzsch STA 409 CD) [23]; in fact, instead of solar radiation, Gálvez et al. [23] used the thermal energy produced by thermogravimetric instrument as the heat required for reaction. The basic principle of a thermogravimeter is the measurement of mass change over time as temperature changes (dynamic runs) or is fixed (isothermal runs). For kinetic studies, the isothermal runs are more favored and it is possible to guess kinetic parameters and mechanism from performance of a chemical reaction at different temperatures with temperature treated as a parameter (that is, a fixed temperature for an individual run but different relative to temperatures of other runs). The raw kinetic data used in our study were taken from isothermal runs of Ref. [23]. Usually, other instruments and techniques such as Fourier-transform infrared spectroscopy (FTIR), mass spectrometry, and gas chromatography $(\mathrm{GC})$ are coupled to thermogravimetric operations for analytical purposes; in Ref. [23], GC method was used in combination with thermogravimetric operations. In general, Ref. [23] is a very comprehensive study with various experimental techniques used but only some parts of it is pertinent to the subject of our study.

After rearranging the differential equation in Eq. (1) and taking integral from both sides, the function $g(a)$ in Table A1 can be created:

$$
\int_{0}^{a} \frac{d a}{f(a)}=\int_{0}^{t} k d t \Rightarrow g(a)=k t
$$

In Ref. [23], the D3 model was used for fitting of charcoal curves and the R3 model was utilized for petcoke curves; our paper, however, illustrates the determination of correct kinetic equations more systematically and more mathematically and with assistance of the behavior of experimental kinetic data.

\section{Calculation of rate coefficient $(k)$}

The rate coefficient $k$ is one of the most important quantities in chemical kinetics and in most cases, including those in this study, has a fixed value by fixing temperature. What should be done is to obtain the rate coefficients at certain temperatures from 
correct kinetic equations in order for calculating the activation energies (another important quantity) and to compare these energies for selecting the most powerful reducing agent for reduction of metal oxide. The correct kinetic equation is unknown initially and the strategy is to calculate the rate coefficients for 18 equations and the detection of correct kinetic equation by some "mathematical filters" (introduced shortly) which are exerted on the calculated values of $k$. For calculation of $k$ for any 1 of 18 equations in a fixed temperature, 4 methods can be considered in initial sight but only one optimum method must be selected. After selection of best method, 3 other methods are eliminated from discussions. Then, various mathematical tests, all relevant to selected method and introduced shortly, are presented for selection of best kinetic equation from among 18 mathematical equations; the selected rate coefficient comes from this best equation. It is important not to confuse things; in short, at first, only 1 method is selected from among 4 methods and then, all 18 equations are examined by various mathematical tests based on the selected method to give one selected equation and therefore, one selected rate coefficient. The 4 methods are:

\section{Method 1}

To extract the mathematical functions $a(t ; k)$ from functions in Table A1 and to fit the experimental data of $a$ versus $t$ to the functions $a(t ; k)$ for finding the rate coefficient $k$.

\section{Method 2}

The same as method 1 except that in this method, $t$ is in the role of dependent variable and $a$ in the role of independent one.

Since the purpose is to compare 18 equations together and the shift of variables is done in all 18 equations, this shift is of no problem from standpoint of mathematical logics.

\section{Method 3}

To apply Eq. (1).

In this method, the curve of experimental data of $a$ versus $t$ is plotted and then, the quantity $d a / d t$ is calculated in every point of the curve. The calculation of $d a / d t$ is possible from two ways. First is to use the numerical algorithms for calculation of $d a / d t$ but this method can have appreciable error. Second is to fit as exact as possible the experimental data to a mathematical function compatible to the boundary conditions of experiment. It is not necessary that this function to be from those in Table A1 because this function is only an auxiliary one; in fact, the fundamental properties of this function must be the exactness in fitting and the compatibility to the boundary conditions of experiment. Considering $a=0$ in $t=0$ and $a=1$ in $t=\infty$ and the particular shape of the experimental data of $a$ versus $t$, the correct selection and the best choice is a function of the general form given in Eq. (3):

$$
a(t)=1-\exp \left(-b t^{c}\right) \quad \text { s.t. } \quad b>0, c>0 .
$$

where s.t. denotes "subject to" or "such that". After determination of function $a(t)$, or more precise $a(t ; b, c)$, the derivative of this function is calculated and by inserting the experimental data of $t$ in it, the quantity $d a / d t$ is calculated in every point of the experimental curve. The quantity $f(a)$ in these points can be calculated by means of 
experimental data of $a$ and Table A1. Considering Eq. (1), the value of $k$ can be calculated through two routes. In the first route, the curve of $d a / d t$ versus $f(a)$ is plotted and the slope of linear fitting function gives the value of $k$. In the second route, the value of $k$ is determined from Eq. (1) for each datum of $a$ and the average of obtained values of $k$ gives the final value for $k$. It turned out for our data that two routes give essentially identical value for $k$; the second route was adopted in this study.

\section{Method 4}

The same as method 3 except that in this method, Eq. (2) plays the role.

Now, the advantage(s) and disadvantage(s) of these 4 methods are expressed in order to select only one optimal method and to throw away other three methods. About method 1, it should be said that it is not possible to extract $a(t ; k)$ for all functions in Table A1. Since the goal is to compare all 18 equations together, the method 1 is not an interesting one. Also, this method relies only on agreement between experimental data and fitting curve and uses only statistical quantities like RSQ (coefficient of determination or $R$-square or $R^{2}$ ), RMSE (root mean squared error), and SSE (sum of squares of error) [30] for finding $k$. One of the permanent problems in chemical kinetics and especially in SSCK has been the satisfactory agreement between data and fitting curve while this fitting function in fact does not represent the real mechanism of reaction but the apparent agreement is reflected well in statistical quantities of fitting [30]. Additionally, the values of $a$ are small and application of them in statistical quantities, which use them several times, introduces some error. For method 2, it should be said that this way does not have the fault of method 1 for extracting the function $t(a ; k)$ from Table A1. However, the other faults of method 1 is existent for method 2. About methods 3 and 4, it should be said that the method 4 is more exact because the mathematical form of function $g(a)$ is definite and analytically obtained and extra steps of method 3 and unwanted resulted errors do not exist. As a result, the method 4 can be taken as the fundamental and principal method and various mathematical tests are derived from it (method 4) for examination of 18 equations; these tests determine the correct kinetic equation and therefore, the correct rate coefficient in an especial fixed temperature. Appendix B in Online Resource describes the usage of method 4 more mathematically and rigorously, but for those uninterested in mathematical details, Appendix $\mathrm{B}^{*}$ in Online Resource is essentially the same as Appendix B but without mathematical equations; only the results are mentioned in paper.

It is clear that the more powerful and flexible the mathematical programming used, the more precise the huge amounts of calculations and because of this key point, the calculations in this study were performed by several mathematical programs written in the powerful and fast languages of MATLAB and $C$ and combination of them known as MEX Functions.

\section{Results and discussion}

\section{Calculation of activation energy $\left(E_{a}\right)$}

After detecting the correct kinetic equation and finding the corresponding rate coefficient, it should be noted that all actions performed (mentioned more rigorously in Appendix B in Online Resource) are for reaction at one certain temperature. Therefore, all 
those long steps must be accomplished also for other temperatures. After obtaining the values of $k$ for all temperatures of reaction, the activation energy of reaction can be calculated. In some studies, the well-known equation of Arrhenius has been used [23, 3133]:

$$
k(T)=A \exp \left(-E_{a} / R T\right)
$$

$T, A$, and $R$ are thermodynamic temperature, pre-exponential factor and gases constant, respectively. In general, the calculation of activation energy by non-linear regression from non-linear Eq. (4) is more exact relative to linear regression of logarithmic form of Eq. (4); the reason has to do with the statistical weights and residuals of data and is a detailed statistical discussion. The Arrhenius equation is a form of Hood equation [34]:

$$
k(T)=A \exp (-B / T)
$$

where $B$ is a constant. The questionable point in Eq. (4) is the independency of activation energy from temperature. Since on one hand, the reactions in SSCK are particular reactions and occurred at high temperatures and on the other hand, it is completely possible to obtain the values of $k$ at different temperatures from different kinetic equations (because of different mechanisms), it is a logical action to take into account the possibility of change of activation energy with temperature. Thus, the original form of Arrhenius equation can be a more exact definition of activation energy [35]:

$$
E_{a}(T)=R T^{2} \frac{d \ln k}{d T}
$$

Using Eq. (6) analytically is more exact relative to numerical usage of it and this requires the function $k(T)$ to be introduced. The function $k(T)$ can be found by curve fitting of obtained values of $k$ at different temperatures but the general mathematical form of function $k(T)$ should be selected carefully. One of the proposed forms is as [34-36].

$$
k(T)=A T^{s} \exp \left(-E_{a} / R T\right)
$$

in which, $s$ is usually a small positive integer related to statistical thermodynamic discussions [35]. Equation (7) is a generalized form of Arrhenius equation and acts more exact in some cases. It will be more exact to take $E_{a} / R$ in Eq. (7) as a constant like $C$ and to utilize Eq. (6) to obtain activation energy as $E_{a}=C R+$ sRT. Considering these points, the perfect mathematical form of Eq. (8) can be a suitable choice and was utilized in this study:

$$
k(T)=A T^{B} \exp \left(-C / T^{D}\right) \quad \text { s.t. } \quad \mathrm{A}>0, \mathrm{~B} \geq 0, \mathrm{C}>0, \mathrm{D}>0 .
$$

Since Eq. (8) contains 4 parameters, the number of data points (temperatures) needed for determination of 4 parameters from fitting should be at least 4 and therefore, for cases like molar ratio 1:2 with only 3 data points (introduced shortly), $D$ was taken as 1 . Combining Eq. (6) and Eq. (8), the corresponding activation energy can be calculated as 


$$
E_{a}(T)=R T\left(B+\frac{C D}{T^{D}}\right)
$$

\section{Reactions of $\mathrm{MgO}$ with carbonic reductants}

The general form of reaction of $\mathrm{MgO}$ with carbonic reductants at high temperatures can be shown as

$$
M g O(s)+C(s) \rightarrow M g(g)+C O(g)
$$

Molar ratio of $\mathrm{MgO}$ to reductant in all reactions performed was 1:1 or 1:2 [23]. The trend of calculations is described in details for one reaction in a certain molar ratio and only the results are presented for other cases.

\section{Reaction of $\mathrm{MgO}$ with charcoal in molar ratio 1:1 at $T=1723.15 \mathrm{~K}$}

The 18 mathematical tests exerted on 18 different kinetic equations in order to clarify the correct one can be collected in a table in which, the rows represent 18 tests and the columns are abbreviations for kinetic equations selected by first 15 tests. Table 1 is an illustration and the quantities with number 1 are for curves of $g(a)$ versus $t$, the quantities with number 2 for curves of $k$ versus $t$ and the quantities with number 3 for curves of $t$ versus $a$.

As can be seen in Table 1, from first 15 tests, only 3 tests confirm a mechanism other than D4. Considering the power of tests, it is obvious that the most logical selection for correct kinetic equation is D4. Therefore, the rate coefficient is taken from equation D4 and two other equations (D3 and F3) are deleted for this case. The values of $k$ for

Table 1 The results of applying different tests to the different kinetic equations for determination

\begin{tabular}{|c|c|c|c|c|}
\hline No. & Test & D3 & D4 & F3 \\
\hline 1) & Slope (1) & & $\checkmark$ & \\
\hline 2) & Intercept (1) & & $\checkmark$ & \\
\hline 3) & RSQ (1) & & & $s$ \\
\hline 4) & RMSE (1) & & $\checkmark$ & \\
\hline 5) & SSE (1) & & $\checkmark$ & \\
\hline 6) & Slope (2) & & $\checkmark$ & \\
\hline 7) & Intercept (2) & & $\checkmark$ & \\
\hline 8) & RSQ (2) & $\checkmark$ & & \\
\hline 9) & RMSE (2) & & $\checkmark$ & \\
\hline 10) & SSE (2) & & $\checkmark$ & \\
\hline 11) & Variance & & $\checkmark$ & \\
\hline 12) & SD & & $\checkmark$ & \\
\hline 13) & RSD & & & $\checkmark$ \\
\hline 14) & Covariance & & $\checkmark$ & \\
\hline 15) & Range & & $\checkmark$ & \\
\hline 16) & RSQ (3) & & & $\checkmark$ \\
\hline 17) & RMSE (3) & & & $\checkmark$ \\
\hline 18) & SSE (3) & & & $\checkmark$ \\
\hline
\end{tabular}
of average $\mathrm{k}$ for reaction of $\mathrm{MgO}$ with charcoal in molar ratio 1:1 and at temperature $1723.15 \mathrm{~K}$ 
equations D3, D4 and F3 as well as their optimized values are presented in Table 2. It is useful to mention this point that $\mathrm{F}$ mechanisms have been borrowed from other branches of chemical kinetics in which, contrary to SSCK, the concepts of concentration and collision are meaningful. Therefore, F mechanisms are in a lower grade compared to other mechanisms of SSCK. The defeat in 13 tests and the better fitting by respective $t(a ; k)$ reflected in RSQ (3), RMSE (3), and SSE (3) in Table 1 for F3 equation is in fact a clear example of wrong conclusions based on only the statistical quantities of fitting like RSQ; as can be seen in Table 2, the value of $k$ for F3 model is about two orders of magnitude larger than that of D4 model and this affects the calculation of activation energy significantly. In fact, the erroneous calculation of activation energy can be very detrimental with respect to some critical decisions in industry such as identification of the bottleneck of process. Figure 1a illustrates the experimental data as well as final selected equations for charcoal in molar ratio 1:1 at different temperatures; except for $1823.15 \mathrm{~K}$, all other temperatures follow D4 equation. Fig. 1b shows the experimental data fitted by Eq. (3) for these cases; this equation lacks the fundamental discussions about mechanism and emphasizes only on fitting and hence, cannot be used for calculation of activation energy; Appendix $C$ in Online Resource shows an interesting usage of Eq. (3) regarding the estimation of $90 \%$ of reaction time. Table 3 reports the abbreviations of selected kinetic equations and also the corresponding optimized values of $k$ for reactions of $\mathrm{MgO}$ with carbonic reductants in different molar ratios at different temperatures. In the study of Gálvez et al. [23], the D3 equation was used for all charcoal cases and the R3 equation for all petcoke cases; RSQ and RMSE were the important criteria for selection of these models in Ref. [23].

In general, the unsatisfactory fitting by some selected kinetic equations results from the lack of enough evolution of theories in SSCK and this problem is considered as the largest challenge in SSCK. In fact, it can be said that among various fields of chemical kinetics, SSCK has the most amount of ambiguity and obscurity and the elucidation of its mysteries requires the more attention, time and cost, relative to what is in action at present.

The mechanisms of chemical reactions have been always a very challenging subject in Chemistry, and this difficulty is even more severe in the solid state. As can be seen in Table 3, except for charcoal in molar ratio 1:1 and at temperature $1823.15 \mathrm{~K}$ that obeys D3 mechanism, other cases follow D4 mechanism. In all, it is inferred that the diffusion is the rate-determining step in the processes involved in this study. Since the boiling temperature of $\mathrm{Mg}$ metal is about $1363 \mathrm{~K}$ and considering the higher temperatures studied in this paper, the produced magnesium in Eq. (10) will be as gaseous and

Table 2 The values of average $k$ obtained from equations D3, D4, and F3 and the corresponding optimized values for reaction of $\mathrm{MgO}$ with charcoal in molar ratio 1:1 and at temperature 1723.15

\begin{tabular}{ll} 
K & \\
\hline Eq. & $\mathbf{k} / \mathbf{m i n}^{\mathbf{- 1}}$ \\
\hline D3 & $3.1358 \times 10^{-5}$ \\
D3 (Opt.) & $3.8897 \times 10^{-5}$ \\
D4 & $3.0143 \times 10^{-5}$ \\
D4 (Opt.) & $3.6997 \times 10^{-5}$ \\
F3 & $2.3836 \times 10^{-3}$ \\
F3 (Opt.) & $2.1913 \times 10^{-3}$ \\
\hline
\end{tabular}




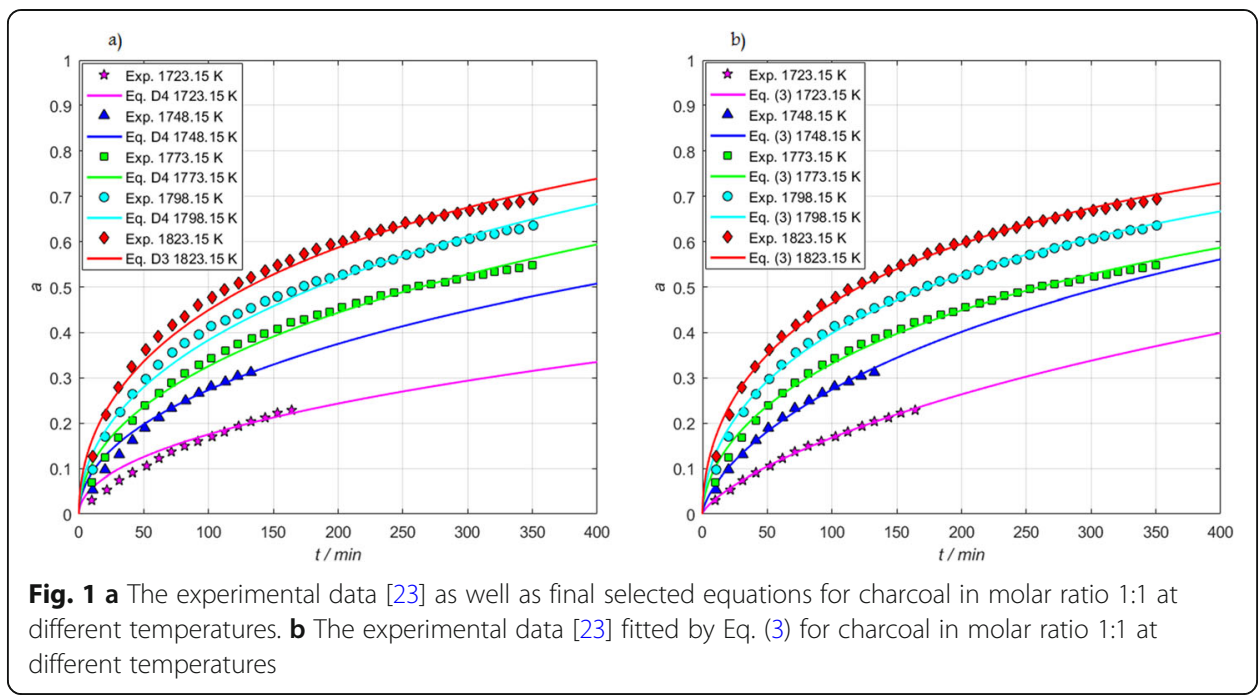

hence, it can be said that the products of reaction exit from reaction zone and thus, the rate-determining step of diffusion concerns probably only the reactants. The significant point is that the melting point of a solid has inverse relation with diffusion [37] and hence, the high melting points of reactants in Eq. (10) are compatible with the conclusion that diffusion is the rate-determining step.

Since D4 is an extension to D3 model, the numerical values of rate coefficients for D3 and D4 models in the identical conditions are not very different and this fact was observed in this study frequently; Table 2 contains one instance. Therefore, it can be said that the D4 equation can be taken as the fundamental kinetic model for describing the kinetic behavior of reaction of $\mathrm{MgO}$ with charcoal and with petcoke, each in molar ratios 1:1 and 1:2 and at different temperatures. The derivation of mathematical equation for D4 mechanism using first Fick law is discussed in detail in Ref. [27].

The subtle and significant point in Table 3 is the very small values of rate coefficients for reactions in the solid state and especially, for reaction of $\mathrm{MgO}$ with carbonic materials according to Eq. (10), in spite of very large temperatures involved. In fact, it can be said that if Eq. (10) is a part of a chemical process in a facility, it will be a limiting step in entire process. This limiting property is highlighted when comparison with the reactions, for example, in solution; for instance, the reaction of $\mathrm{C}_{2} \mathrm{H}_{5} \mathrm{I}$ with $\mathrm{OH}^{-}$in

Table 3 The abbreviations of selected kinetic equations and also the corresponding optimized values of $\mathrm{k} / \mathrm{min}^{-1}$ for reactions of $\mathrm{MgO}$ with carbonic reductants in different molar ratios and at different temperatures

\begin{tabular}{lllll}
\hline & MgO:Charcoal (1:1) & MgO:Charcoal (1:2) & MgO:Petcoke (1:1) & MgO:Petcoke (1:2) \\
\hline $1723.15 \mathrm{~K}$ & $\mathrm{D} 4$ & - & $\mathrm{D} 4$ & - \\
& $3.6997 \times 10^{-5}$ & & $1.0785 \times 10^{-5}$ & \\
$1748.15 \mathrm{~K}$ & $\mathrm{D} 4$ & - & $\mathrm{D} 4$ & - \\
& $9.4982 \times 10^{-5}$ & & $2.7457 \times 10^{-5}$ & \\
$1773.15 \mathrm{~K}$ & $\mathrm{D} 4$ & $\mathrm{D} 4$ & $\mathrm{D} 4$ & $\mathrm{D} 4$ \\
& $1.3911 \times 10^{-4}$ & $4.0373 \times 10^{-4}$ & $1.3286 \times 10^{-4}$ & $3.3743 \times 10^{-4}$ \\
$1798.15 \mathrm{~K}$ & $\mathrm{D} 4$ & $\mathrm{D} 4$ & $\mathrm{D} 4$ & $\mathrm{D} 4$ \\
& $1.9955 \times 10^{-4}$ & $5.0920 \times 10^{-4}$ & $2.5443 \times 10^{-4}$ & $5.4242 \times 10^{-4}$ \\
$1823.15 \mathrm{~K}$ & $\mathrm{D} 3$ & $\mathrm{D} 4$ & $\mathrm{D} 4$ & $\mathrm{D} 4$ \\
& $3.2579 \times 10^{-4}$ & $6.8116 \times 10^{-4}$ & $4.2046 \times 10^{-4}$ & $8.3734 \times 10^{-4}$ \\
\hline
\end{tabular}


ethanol has a rate coefficient of $0.119 \mathrm{~L} \mathrm{~mol}^{-1} \mathrm{~s}^{-1}$ at $363.8 \mathrm{~K}$ [35], where $L$ denotes liter. This limiting nature of reactions in the solid state will be reflected at high values for activation energy, discussed shortly.

\section{Activation energies at different conditions}

The calculation of activation energies requires a good fitting of obtained values of $k$. Figure 2 shows the final values of $k$ from Table 3 as well as curves of $k(T)$ obtained from fitting by Eq. (8); in figures of this study, C11 is applied to charcoal 1:1, C12 to charcoal 1:2, P11 to petcoke 1:1 and P12 to petcoke 1:2. The parameters obtained from fitting and the relevant statistical quantities of fitting [30] are reported in Table 4. The interesting point in Table 4 is that the values of parameter $\mathrm{D}$ for charcoal 1:1 and petcoke 1:1 are practically 1 ; as pointed out below Eq. (8), because of 5 values of $k$ for 5 temperatures for molar ratio 1:1 for both charcoal and petcoke, $D$ can be set as fourth parameter in 1:1 cases (unlike molar ratio 1:2 with $D$ equal to 1 from beginning). Because of low number of points in the case of molar ratio 1:2, the corresponding fittings in Fig. 2 and the resulted activation energies are not very reliable; in fact, because of equality of number of parameters and number of experimental data points in molar ratio 1:2, the quantity of RMSE is infinity, as can be seen in Table 4 and verifiable from Eq. (B7) in Appendix B in Online Resource. In general, the more the number of experimental data, the more precise the calculations.

The values of $E_{a}$ at different temperatures, the values of SD, RSD and range for $E_{a}$, the mean value of $E_{a}, E_{a}$ obtained from non-linear regression of Arrhenius equation, $E_{a}$ obtained from linear regression of Arrhenius equation (using logarithmic linear form as

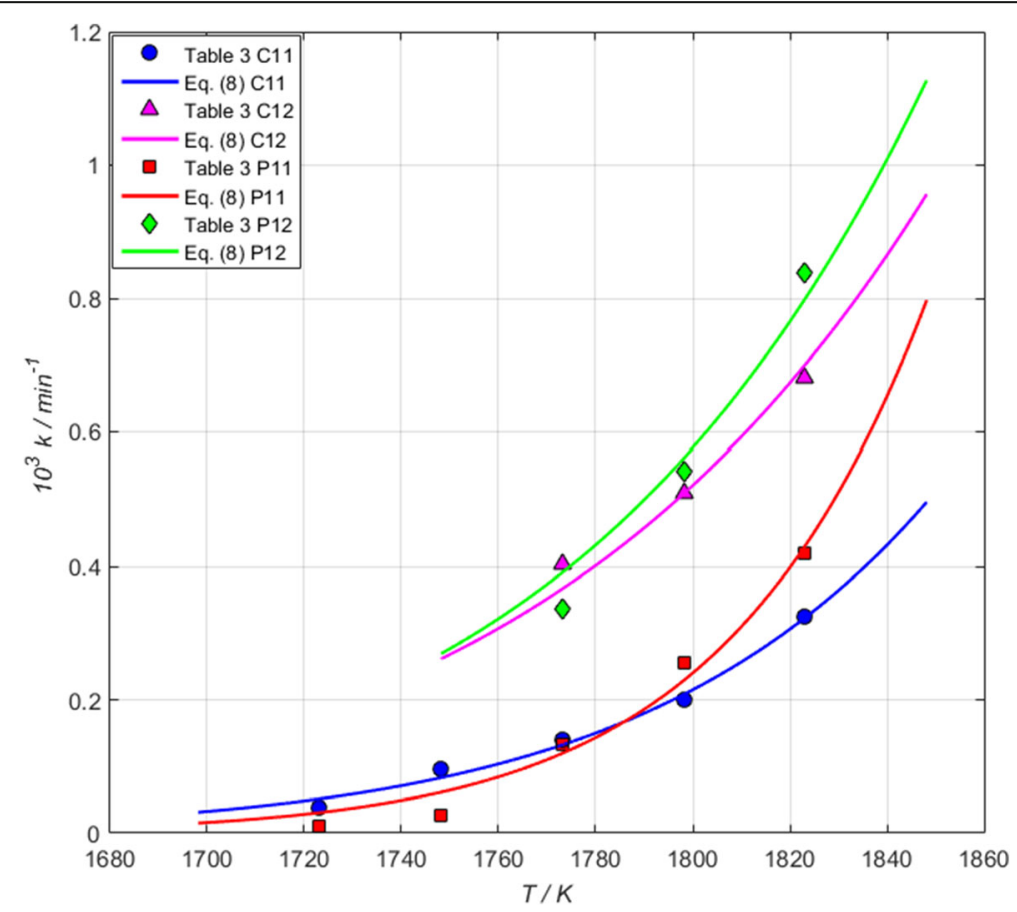

Fig. 2 The final values of $k$ as well as curves of $k(T)$ for reactions of $\mathrm{MgO}$ with carbonic reductants in different molar ratios and at temperatures $1723.15 \mathrm{~K}, 1748.15 \mathrm{~K}, 1773.15 \mathrm{~K}, 1798.15 \mathrm{~K}$, and $1823.15 \mathrm{~K}$ 
Table 4 The parameters obtained from fitting of final values of $k$ by Eq. (8) and the relevant statistical quantities of fitting [30] for reactions of $\mathrm{MgO}$ with carbonic reductants in different molar ratios and at temperatures 1723.15 K, 1748.15 K, 1773.15 K, $1798.15 \mathrm{~K}$, and $1823.15 \mathrm{~K}$

\begin{tabular}{|c|c|c|c|c|}
\hline & MgO:Charcoal (1:1) & MgO:Charcoal (1:2) & MgO:Petcoke (1:1) & MgO:Petcoke (1:2) \\
\hline $\mathrm{A} /\left(\mathrm{K}^{-\mathrm{B}} \min ^{-1}\right)$ & 881243424.7861 & 6745162.4300 & 908504046.5483 & 84223579.3924 \\
\hline B & 0.2510 & $3.1695 \times 10^{-13}$ & 1.6029 & $2.2265 \times 10^{-14}$ \\
\hline$C / K^{D}$ & 70055.7717 & 41910.0601 & 139511.1051 & 46272.3206 \\
\hline D & 1.0307 & 1 & 1.0850 & 1 \\
\hline RSQ & 0.9903 & 0.9548 & 0.9789 & 0.9631 \\
\hline RMSE & $2.1819 \times 10^{-5}$ & Infinity & $4.9679 \times 10^{-5}$ & Infinity \\
\hline SSE & $4.7609 \times 10^{-10}$ & $1.7711 \times 10^{-9}$ & $2.4680 \times 10^{-9}$ & $4.6591 \times 10^{-9}$ \\
\hline RSQ $_{\text {NL_Arr }}{ }^{a}$ & 0.9902 & 0.9532 & 0.9311 & 0.9805 \\
\hline RMSE $_{\text {NL_Arr }}$ & $1.2662 \times 10^{-5}$ & $4.2859 \times 10^{-5}$ & $5.1820 \times 10^{-5}$ & $4.9617 \times 10^{-5}$ \\
\hline$S S E_{N L \_A r r}$ & $4.8101 \times 10^{-10}$ & $1.8369 \times 10^{-9}$ & $8.0558 \times 10^{-9}$ & $2.4618 \times 10^{-9}$ \\
\hline RSQL_Arr & 0.9636 & 0.9947 & 0.9658 & 0.9997 \\
\hline RMSE $E_{L \_A r r}$ & 0.1811 & $2.6988 \times 10^{-2}$ & 0.3291 & $1.1373 \times 10^{-2}$ \\
\hline SSE $E_{L_{-} \text {Arr }}$ & $9.8376 \times 10^{-2}$ & $7.2837 \times 10^{-4}$ & 0.3249 & $1.2935 \times 10^{-4}$ \\
\hline $\left.\mathrm{RSQ}_{\text {Ref [ }} 23_{]}\right]$ & 0.9421 & - & 0.9895 & - \\
\hline $\mathrm{RMSE}_{\text {Ref [23]. }}$ & 0.02 & - & 0.027 & - \\
\hline $\operatorname{SSE}_{\text {Ref [23]. }}$ & - & - & - & - \\
\hline
\end{tabular}

${ }^{\mathrm{a}}$ Non-linear Arrhenius Fitting

${ }^{\mathrm{b}}$ Linear Arrhenius Fitting

in Ref. [23]) and $E_{a}$ from Ref. [23] are all holus-bolus collected in Table 5. The reasons of equal $E_{a}$ for each of molar ratio 1:2 are the essentially zero value of $B$ and exact value of 1 for $D$ that according to Eq. (9), cause this property.

In Ref. [23], $E_{a}$ was obtained only for 1:1 molar ratio for both reducing agents and 1: 2 molar ratio was not treated in this regard; according to Table 5, contrary to Ref. [23], $E_{a}$ for 1:1 molar ratio for petcoke case is larger than that of charcoal case; introduced

Table 5 The comparison of values of $E_{a} /\left(\mathrm{kJ} \mathrm{mol}^{-1}\right)$ obtained from different methods as well as the relevant statistical quantities for reactions of $\mathrm{MgO}$ with carbonic reductants in different molar ratios and at temperatures $1723.15 \mathrm{~K}, 1748.15 \mathrm{~K}, 1773.15 \mathrm{~K}, 1798.15 \mathrm{~K}$, and $1823.15 \mathrm{~K}$

\begin{tabular}{lllll}
\hline & MgO:Charcoal (1:1) & MgO:Charcoal (1:2) & MgO:Petcoke (1:1) & MgO:Petcoke (1:2) \\
\hline$E_{a, 1723.15}$ & 481.2313 & - & 690.8303 & - \\
$E_{a, 1748.15}$ & 481.0725 & - & 690.3459 & - \\
$E_{a, 1773.15}$ & 480.9167 & 348.4596 & 689.8742 & 384.7295 \\
$E_{a, 1798.15}$ & 480.7639 & 348.4596 & 689.4146 & 384.7295 \\
$E_{a, 1823.15}$ & 480.6140 & 348.4596 & 688.9670 & 384.7295 \\
SD & 0.2440 & $4.0194 \times 10^{-14}$ & 0.7366 & $6.9619 \times 10^{-14}$ \\
RSD & $5.0744 \times 10^{-2}$ & $1.1535 \times 10^{-14}$ & 0.1068 & $1.8095 \times 10^{-14}$ \\
Range & 0.6174 & $5.6843 \times 10^{-14}$ & 1.8633 & 0 \\
Mean & 480.9197 & 348.4596 & 689.8864 & 384.7295 \\
$E_{a, \text { NL_Arr }}{ }^{a}$ & 487.1059 & 349.7380 & 501.1278 & 411.4653 \\
$E_{a, \text { L_Arr }}{ }^{2}$ & 533.4443 & 281.0194 & 1000.5536 & 488.6408 \\
$E_{a, \text { Ref. [2] }}$ & 468.4 & - & 419.1 & - \\
\hline
\end{tabular}

${ }^{\mathrm{a}}$ Non-linear Arrhenius Fitting

${ }^{\mathrm{b}}$ Linear Arrhenius Fitting 
shortly, the quantitative validation of method using experimental data will clarify that our treatment gives more real values for $E_{a}$, relative to treatment of Re [23].. It is also noteworthy that in Table 5, the values of $E_{a}$ for an individual carbonic reductant but in different molar ratios are different; more has been said about this difference in Appendix D in Online Resource. In the study of Rongti et al. [24], only partly similar to our work, they examined the reaction between $\mathrm{MgO}$ and graphite powders in a dynamic (non-isothermal) manner in the temperature range 293 to $1973 \mathrm{~K}$ and obtained the average activation energy equal to $208.29 \mathrm{~kJ} \mathrm{~mol}^{-1}$ for $0.1<a<0.25$ and $374.13 \mathrm{~kJ}$ $\mathrm{mol}^{-1}$ for $0.25<a<0.5$; these values were found for molar ratio 1:2 (MgO:C); they also calculated the activation energy using transition state theory (TST) as $470 \mathrm{~kJ} \mathrm{~mol}^{-1}$ and introduced a chemical mechanism but did not discuss the kinetic equations. In a study by Shu et al. [38], the isothermal reduction of Scheelite $\left(\mathrm{CaWO}_{4}\right)$ by silicon $(\mathrm{Si})$ from 1423 to $1523 \mathrm{~K}$ was accomplished from a kinetic viewpoint and it turned out that both D3 and D4 models can describe the kinetics of reaction well; Arrhenius equation (in logarithmic linear form) was used for calculation of $E_{a}$ and the values of 379.93 and $387.16 \mathrm{~kJ} \mathrm{~mol}^{-1}$ were obtained for D3 and D4 models, respectively.

One point clearly observable in Table 5 is the high values of activation energy for reactions in the solid state, relative to those in other phases; for example, the reaction of $\mathrm{C}_{2} \mathrm{H}_{5} \mathrm{I}$ with $\mathrm{OH}^{-}$in ethanol has $E_{a}$ equal to $90.3744 \mathrm{~kJ} \mathrm{~mol}^{-1}$, obtained from Arrhenius equation in logarithmic linear form [35]. In fact, the highness for values of $E_{a}$ in Table 5 is rooted in the lowness of $k$ values in Table 3. Consequently, it can be inferred that the reaction of $\mathrm{MgO}$ with carbonic materials (Eq. (10)) can be considered as the limiting step in a process.

\section{Quantitative validation of method using experimental data}

Because of significance of activation energy in the design of chemical processes in industry and for suitable treatment of slow reactions (chemical bottlenecks), the comparison of $E_{a}$ values is of critical importance. One of the important results obtained from Fig. 2 and Table 5 is that, contrary to Ref. [23], the values of average $E_{a}$ in both molar ratios are larger for petcoke than those for charcoal. In this section, the quantitative validation of adopted method in present paper is introduced to show the validity of conclusions about activation energy; before that, it will be appropriate to mention a related subtle point regarding change of rate coefficient with temperature.

In general, for finding the amount of sensitivity of a reaction to temperature change, the quantity of $d k / d T$ is a good choice. Rewriting Eq. (6) as Eq. (11),

$$
\frac{d k}{d T}=\frac{k E_{a}(T)}{R T^{2}}
$$

it is obvious that both $k$ and $E_{a}$ appear as effective factors but usually, it is the quantity of $d \ln k / d T$ that is used in this regard. The point is that $d \ln k=d k / k$ is, in fact, the limit of $\Delta k / k$ when $\Delta T \rightarrow 0$ and the fraction of $\Delta k / k$ is a more suitable quantity for investigation of sensitivity compared to $\Delta k$. Therefore, Eq. (6) is more appropriate compared to Eq. (11) for evaluation of sensitivity to temperature. Rearranging Eq. (6) as Eq. (12), 


$$
\frac{d \ln k}{d T}=\frac{E_{a}(T)}{R T^{2}}
$$

and it is obvious that $k$ does not appear as a contributing factor in right hand side of Eq. (12). Therefore, according to Eq. (12), the larger the activation energy for a reaction, the higher the sensitivity of that reaction to temperature; this sensitivity approaches zero when $T \rightarrow \infty$ and approaches infinity when $T \rightarrow 0$.

Considering Eq. (12) and Table 5, petcoke with molar ratio 1:1 will have the most sensitivity to temperature. Figure $3 \mathrm{a}, \mathrm{b}$, practically identical but drawn in the different styles, confirms this conclusion. If the number of data would be more and equal for all cases, the sensitivity of petcoke to temperature would flaunt even more. In Fig. 2, it is also obvious that the numerical values of $k$ and therefore, the corresponding fitting curve for petcoke 1:1 are lower than those of charcoal 1:1 at not very high temperatures but are higher at very high temperatures; the same situation is observed for numerical values of $k$ for petcoke 1:2 relative to charcoal 1:2; the reason of not observing this trend for corresponding fitting curve of petcoke 1:2 relative to charcoal 1:2 is the low number of data points and high curvature of fitting function required for petcoke 1:2, leading to disability of fitting method in giving a good fit.

More quantitatively and in principle, the areas under experimental data in Fig. 3a, b can be calculated numerically and compared; this comparison would be more accurate if initial and final times would be the same for all experimental runs. Notwithstanding, for an approximate exploration, these areas were calculated for charcoal 1:1 and petcoke 1:1 at temperature interval $T=1773.15 \mathrm{~K}$ to $T=1823.15 \mathrm{~K}$ with the initial point taken in $40 \mathrm{~min}$ and the final point in $348 \mathrm{~min}$; the reason of such selections was the relatively good coverage of experimental data, as can be seen in Fig. 3a, b. Figure 4a shows this quantitative comparison of $A U C$, the area under curve, obtained by numerical integration using a program written in MATLAB; in accordance with Eq. (12) and following the "overtaking" behavior observed in Figs. 2 and 3a, b, petcoke 1:1 is more sensitive to temperature change and this sensitivity is especially large in lower temperatures. Also, by noting Fig. 3a, b, it can be said that the temperature $T=1773.15 \mathrm{~K}$ is a "jumping temperature" for both charcoal 1:1 and petcoke 1:1 that "excites" the

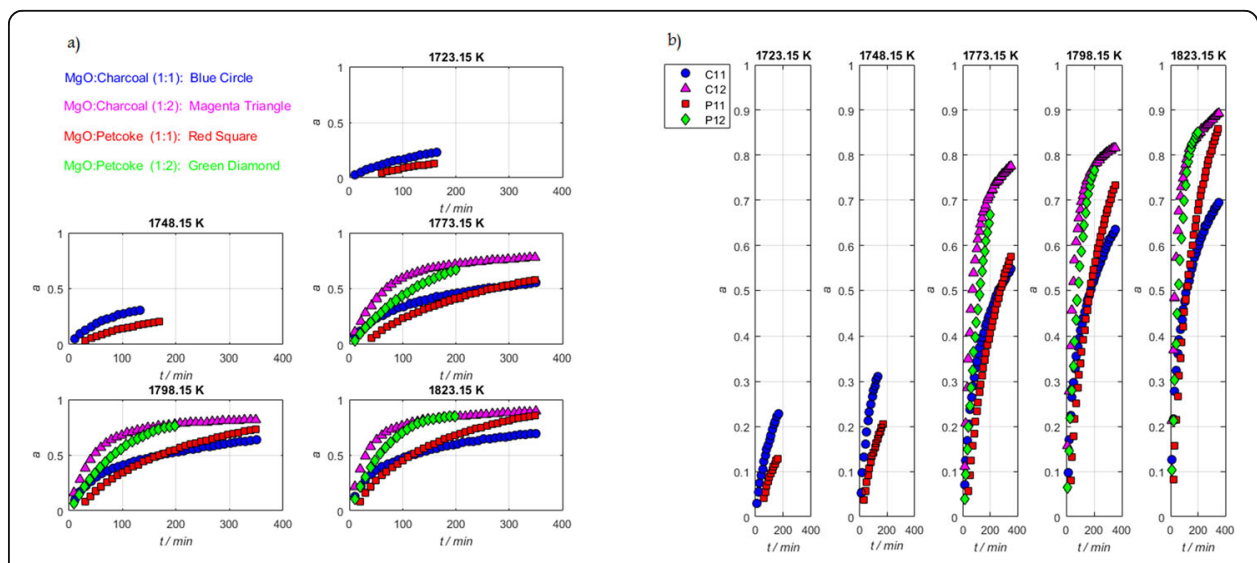

Fig. 3 a The experimental data [23] compared with each other for reactions of $\mathrm{MgO}$ with carbonic reductants in different molar ratios and at different temperatures. $\mathbf{b}$ Other style of plot for data in $\mathbf{a}$ 
reactants for occurrence of chemical reaction; this behavior does not mean that the reaction must be performed at lower temperatures and the point is that the lower the temperature, the more the sensitivity to temperature change. Figure $4 \mathrm{~b}$ shows this behavior better by plotting

$$
\frac{\triangle A U C}{A U C_{1}}=\frac{\left(A U C_{2}-A U C_{1}\right)}{A U C_{1}}
$$

where $\mathrm{AUC}_{1}$ and $\mathrm{AUC}_{2}$ are the areas corresponding to the first and second temperatures in each subinterval in Fig. 4b, respectively; for example, for first temperature interval in Fig. 4b, $\triangle \mathrm{AUC}=\mathrm{AUC}(T=1798.15 \mathrm{~K})-\mathrm{AUC}(T=1773.15 \mathrm{~K})$. Also, the elapse of enough time for a reaction is an important factor in achieving the desired result from that reaction. Therefore, totally, from industry standpoint and in a reasonable amount of reaction time, charcoal with excess molar ratio is the recommended selection for reducing agent at not very high temperatures. At very high temperatures, petcoke with extra molar ratio is a suitable choice and even perhaps, more suitable than charcoal with extra molar ratio, especially if it is possible to provide long time for reaction.

It must be noted that the difference in the behavior of carbonic reducing agents reported in this study is itself a detailed scientific discussion and is relevant to the different microstructural properties of different forms of carbon [39, 40].

In end, it can be said that, like many other reactions in the solid state, diffusion is the dominant process controlling the rate of reactions in this study, especially that the reactants have high melting points. Also, it turned out that the D4 kinetic equation is a powerful mathematical model for kinetic treatment of reactions in the solid state including reactions of this study; Appendices E and F in Online Resource discuss D4 model more thoroughly and Refs [41-54]. are related to Appendix F which addresses the usefulness of D4 equation in analyzing various reactions in Chemistry.

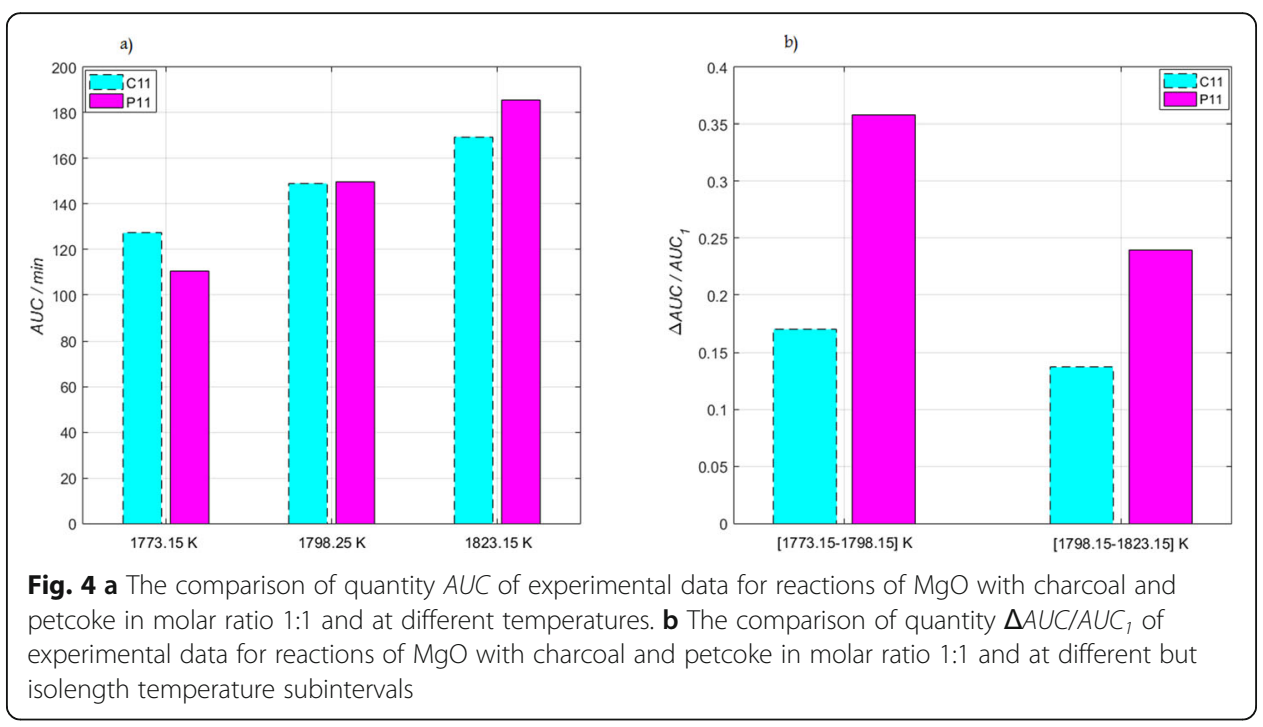




\section{Conclusion}

In this study, a new and detailed combination of mathematical modeling and discrete numerical optimization theory was used by presenting 18 mathematical filters not relying only on statistical quantities of fitting. The purpose of these filters was the determination of correct kinetic equation and therefore, the corresponding rate coefficient from among 18 equations most used at present in solid state chemical kinetics. Then, the obtained values of rate coefficient were fitted by a new fundamental mathematical function. Using the general definition of activation energy and the determined function for rate coefficients, the activation energy was introduced as a function of temperature.

The comparison with previous study was performed and it became clear that, contrary to it, the values of average $E_{a}$ for petcoke are larger than those for charcoal in both molar ratios and besides, the values of $E_{a}$ for an individual carbonic reductant but in different molar ratios are different. Also, the areas under experimental data were calculated and utilized for method validation and comparison. In all, with assistance of experimental data and mathematical discussions, it became clear that for reduction of magnesium oxide to metallic magnesium in a reasonable amount of reaction time, at not very high temperatures, charcoal with excess molar ratio is the most beneficial choice industrially but at very high temperatures, petcoke with extra molar ratio is also suitable and even perhaps, more suitable than charcoal with extra molar ratio, especially if it is possible to provide long time for reaction.

Also, it can be said that, like many other reactions in solid state, diffusion is the dominant process controlling the rate of reactions in this study, especially that the reactants have high melting points. Besides, it turned out that the D4 kinetic equation is a powerful mathematical model for kinetic treatment of reactions in the solid state including reactions of this study.

\footnotetext{
Abbreviations

SSCK: Solid State Chemical Kinetics; TGA: Thermogravimetric Analysis; FTIR: Fourier-transform Infrared Spectroscopy; GC: Gas Chromatography; RSQ (or $R$-square or $R^{2}$ ): Coefficient of Determination; RMSE: Root Mean Squared Error; SSE: Sum of Squares of Error; SD: Standard Deviation; RSD: Relative Standard Deviation; MATLAB: Matrix Laboratory; D4: Ginstling-Brounshtein Diffusion Model (the complete list including D3, R3 and ..., has been collected in Table A1 in Appendix 1 in Online Resource); C11: Charcoal in molar ratio 1:1; C12: Charcoal in molar ratio 1:2; Petcoke: Petroleum Coke; P11: Petcoke in molar ratio 1:1; P12: Petcoke in molar ratio 1:2; NL_Arr: Non-linear Arrhenius; L_Arr: Linear Arrhenius; AUC: Area Under Curve
}

\section{Supplementary Information}

The online version contains supplementary material available at https://doi.org/10.1186/s44147-021-00043-7.

Additional file 1. Table A1 18 principle equations in the solid state chemical kinetics. Table $\mathrm{C} 1$ The values of b, $\mathrm{c}$, $\mathrm{t}_{0.9}$ and statistical quantities of fitting [30] obtained from Eq. (3) (in paper) and Eq. (C1) and the breaking of $\mathrm{t}_{0.9}$ to common units of time for reaction of $\mathrm{MgO}$ with charcoal in molar ratio 1:1 and at temperature 1723.15 K. Table F1 The diversity of chemical reactions in the solid state supported by D4 kinetic model

\section{Acknowledgements}

The authors would like to thank their respective institutes.

\section{Authors' contributions}

The suggestion of subject and methods of this study, the mathematical programming needed for calculations in C and MATLAB languages as well as writing the manuscript were performed by HZ. The mathematical methods were analyzed rigorously and approved by NG. The manuscript was checked by NF comprehensively. All authors read and approved the final manuscript.

Funding

Not applicable. 
Availability of data and materials

The datasets used and/or analyzed during the current study are available from the corresponding author on reasonable request.

\section{Declarations}

\section{Competing interests}

The authors declare that they have no competing interests.

\section{Author details}

${ }^{1}$ Department of Physical Chemistry, Faculty of Chemistry, Ferdowsi University of Mashhad, Mashhad, Iran. ${ }^{2}$ Department of Physical Chemistry, Faculty of Chemistry, University of Isfahan, Isfahan, Iran. ${ }^{3}$ Department of Pure Mathematics, Faculty of Mathematical Sciences, Tarbiat Modares University, Tehran, Iran.

Received: 29 July 2021 Accepted: 21 October 2021

Published online: 18 November 2021

\section{References}

1. House JE (2013) Inorganic chemistry, second edn. Academic Press, Waltham, USA

2. Kokabian B, Ghimire U, Gude VG (2018) Water deionization with renewable energy production in microalgae - microbial desalination process. Renew Energy 122:354-361. https://doi.org/10.1016/j.renene.2018.01.061

3. Nikparsa P, Rauch R, Mirzaei AA (2017) A hybrid of winddiesel technology with biomass-based Fischer-Tropsch synthesis. Monatshefte für Chemie - Chemical Monthly 148(10):1877-1886. https://doi.org/10.1007/s00706-017-1998-5

4. Astaneh M, Roshandel R, Dufo-López R, Bernal-Agustín JL (2018) A novel framework for optimization of size and control strategy of lithium-ion battery based off-grid renewable energy systems. Energy Convers Manag 175:99-111. https://doi. org/10.1016/j.enconman.2018.08.107

5. Shin $H$, Ellinger AE, Nolan HH, DeCoster TD, Lane F (2016) An assessment of the association between renewable energy utilization and firm financial performance. J Bus Ethics 151(4):1121-1138. https://doi.org/10.1007/s10551-016-3249-9

6. Zhang S, Andrews-Speed P, Li S (2018) To what extent will Chinas ongoing electricity market reforms assist the integration of renewable energy? Energy Policy 114:165-172. https://doi.org/10.1016/j.enpol.2017.12.002

7. Yazdani M, Chatterjee P, Zavadskas EK, Streimikiene D (2018) A novel integrated decision-making approach for the evaluation and selection of renewable energy technologies. Clean Techn Environ Policy 20(2):403-420. https://doi.org/1 0.1007/s10098-018-1488-4

8. Lojpur V, Krstić J, Kačarević-Popović Z, Filipović N, Validžić IL (2018) Flexible and high-efficiency Sb2 $\mathrm{S}_{3} /$ solid carrier solar cell at low light intensity. Environ Chem Lett 16(2):659-664. https://doi.org/10.1007/s10311-017-0702-7

9. Henry J, Daniel T, Balasubramanian V, Mohanraj K, Sivakumar G (2020) Enhanced photosensitivity of Bi-doped Cu2 Se thin films prepared by chemical synthesis for solar cell application. Iranian Journal of Science and Technology, Transactions A: Science 44(5):1369-1377. https://doi.org/10.1007/s40995-020-00949-6

10. Hameed AMA (2018) Efficient synthesis of pyrano[2,3-b]pyridine derivatives using microwave or solar energy. Environ Chem Lett 16(4):1423-1427. https://doi.org/10.1007/s10311-018-0744-5

11. Akpinar EK (2019) The effects of some exergetic indicators on the performance of thin layer drying process of long green pepper in a solar dryer. Heat Mass Transf 55(2):299-308. https://doi.org/10.1007/s00231-018-2415-2

12. Yousaf Hameed K, Faisal B, Hanae T, Bernabé Marí S, Saira B, Naveed Ali Kaim K (2019) Modelling of novel-structured copper barium tin sulphide thin film solar cells. Bull Mater Sci 42(5):231. https://doi.org/10.1007/s12034-019-1919-9

13. Najafi-Ghalelou A, Nojavan S, Zare K (2018) Information gap decision theory-based risk-constrained scheduling of smart home energy consumption in the presence of solar thermal storage system. Sol Energy 163:271-287. https://doi.org/1 0.1016/j.solener.2018.02.013

14. Gimpel T, Winter S, Boßmeyer M, Schade W (2018) Quantum efficiency of femtosecond-laser sulfur hyperdoped silicon solar cells after different annealing regimes. Sol Energy Mater Sol Cells 180:168-172. https://doi.org/10.1016/j.solmat.201 8.03.001

15. Matin MA, Rhaman MM, Hakim MA, Islam MF (2020) $\mathrm{Bi}_{(1-y)} \mathrm{Sm}_{\mathrm{y}} \mathrm{FeO}_{3}$ as prospective photovoltaic materials. Bull Mater Sci 43(1):167. https://doi.org/10.1007/s12034-020-02118-2

16. Lashgari M, Zeinalkhani $\mathrm{P}$ (2018) Ammonia photosynthesis under ambient conditions using an efficient nanostructured $\mathrm{FeS}_{2}$ /CNT solar-energy-material with water feedstock and nitrogen gas. Nano Energy 48:361-368. https://doi.org/10.101 6/j.nanoen.2018.03.079

17. Dorouzi M, Mortezapour H, Akhavan H-R, Moghaddam AG (2018) Tomato slices drying in a liquid desiccant-assisted solar dryer coupled with a photovoltaic-thermal regeneration system. Sol Energy 162:364-371. https://doi.org/10.1016/j. solener.2018.01.025

18. Cornaglia LM, Lombardo EA (2018) Pure hydrogen production for low temperature fuel cells. Catal Lett 148(4):10151026. https://doi.org/10.1007/s10562-018-2309-4

19. White-hot energy - Magnesium power - The Economist. https://www.economist.com/technology-quarterly/2010/04/19/ white-hot-energy. Accessed 8 October 2018

20. Hahn R, Mainert J, Glaw F, Lang K-D (2015) Sea water magnesium fuel cell power supply. J Power Sources 288:26-35. https://doi.org/10.1016/j.jpowsour.2015.04.119

21. Hasvold $\varnothing$, Lian T, Haakaas E, Størkersen N, Perelman O, Cordier S (2004) CLIPPER: a long-range, autonomous underwater vehicle using magnesium fuel and oxygen from the sea. J Power Sources 136(2):232-239. https://doi.org/1 0.1016/j.jpowsour.2004.03.023

22. Mordike B, Ebert T (2001) Magnesium: Properties — applications — potential. Mater Sci Eng A 302(1):37-45. https://doi. org/10.1016/S0921-5093(00)01351-4 
23. Gálvez M, Frei A, Albisetti G et al (2008) Solar hydrogen production via a two-step thermochemical process based on MgO/Mg redox reactions-Thermodynamic and kinetic analyses. Int J Hydrog Energy 33(12):2880-2890. https://doi. org/10.1016/j.jijhydene.2008.04.007

24. Rongti L, Wei P, Sano M (2003) Kinetics and mechanism of carbothermic reduction of magnesia. Metall Mater Trans B 34(4):433-437. https://doi.org/10.1007/s11663-003-0069-y

25. Gaisford S, Kett V, Haines P (2016) Principles of thermal analysis and calorimetry, second edn. Royal Society of Chemistry, Cambridge

26. Dickinson C, Heal G (1999) Solid-liquid diffusion controlled rate equations. Thermochim Acta 340-341:89-103. https:// doi.org/10.1016/S0040-6031(99)00256-7

27. Khawam A, Flanagan DR (2006) Solid-state kinetic models: basics and mathematical fundamentals. J Phys Chem B 110(35):17315-17328. https://doi.org/10.1021/jp062746a

28. Sharp JH, Brindley GW, Achar BNN (1966) Numerical data for some commonly used solid state reaction equations. J Am Ceram Soc 49(7):379-382. https://doi.org/10.1111/j.1151-2916.1966.tb13289.x

29. Balaban AT, Klein DJ (2006) Is chemistry the central science? How are different sciences related? Co-citations, reductionism, emergence, and posets. Scientometrics 69(3):615-637. https://doi.org/10.1007/s11192-006-0173-2

30. Curve Fitting Toolbox User's Guide - MATLAB - MathWorks. http://www.mathworks.com/help/pdf_doc/curvefit/curvefit. pdf. Accessed 5 March 2018

31. Czyrski A, Hermann T, Smoląg A (2011) Optimization of a new isoquinoline derivative preparation. React Kinet Mech Catal 104(1):173-180. https://doi.org/10.1007/s11144-011-0331-2

32. Tétényi $P$, Tellinger $O$ (2010) Interaction affinity of nickel promoted molybdena alumina with $C, H$ and $S$ in some catalytic conversions. React Kinet Mech Catal 99:99-109. https://doi.org/10.1007/s11144-009-0104-3

33. Saheb V (2013) Theoretical studies on the kinetics and mechanism of the reaction of atomic hydrogen with carbon dioxide. Kinet Catal 54(6):671-676. https://doi.org/10.1134/S0023158413060104

34. Upadhyay SK (2006) Chemical kinetics and reaction dynamics. Springer, Berlin

35. Levine IN (2009) Physical chemistry, McGraw-Hill Higher Education, New York

36. House JE (2007) Principles of chemical kinetics, Academic Press, Burlington, USA

37. Tiwari GP, Mehrotra RS (2008) Diffusion and melting. Defect and Diffusion Forum 279:23-37

38. Shu Q, Wu J, Chou K (2015) Kinetics Study on Reduction of CaWO4 by Si from 1423 K to 1523 K. High Temperature Materials and Processes 34(8):805-811. https://doi.org/10.1515/htmp-2014-0161

39. Gálvez ME, Hischier I, Frei A, Steinfeld A (2008) Ammonia production via a two-step Al2O3/AIN thermochemical cycle. 3. Influence of the Carbon Reducing Agent and Cyclability. Ind Eng Chem Res 47(7):2231-2237. https://doi.org/10.1021/ ie071244w

40. Gálvez M, Lázaro M, Moliner R (2005) Novel activated carbon-based catalyst for the selective catalytic reduction of nitrogen oxide. Catal Today 102-103:142-147. https://doi.org/10.1016/j.cattod.2005.02.020

41. Alizadehhesari K, Golding SD, Bhatia SK (2012) Kinetics of the Dehydroxylation of Serpentine. Energy Fuel 26(2):783-790. https://doi.org/10.1021/ef201360b

42. Khaki JV, Shalchian H, Rafsanjani-Abbasi A, Alavifard N (2018) Recovery of iron from a high-sulfur and low-grade iron ore. Thermochim Acta 662:47-54. https://doi.org/10.1016/j.tca.2018.02.010

43. Yorulmaz SY, Atimtay AT (2009) Investigation of combustion kinetics of treated and untreated waste wood samples with thermogravimetric analysis. Fuel Process Technol 90(7-8):939-946. https://doi.org/10.1016/j.fuproc.2009.02.010

44. Lepage D, Sobh F, Kuss C, Liang G, Schougaard S (2014) Delithiation kinetics study of carbon coated and carbon free LiFePO4. J Power Sources 256:61-65. https://doi.org/10.1016/j.jpowsour.2013.12.054

45. Zhang J-L, Xing X-D, Cao M-M, Jiao K-X, Wang C-L, Ren S (2013) Reduction kinetics of vanadium titano-magnetite carbon composite pellets adding catalysts under high temperature. J Iron Steel Res Int 20(2):1-7. https://doi.org/10.101 6/S1006-706X(13)60048-5

46. Bai Y, Wu C, Wu F, Yang J-H, Zhao L-L, Long F, Yi B-L (2012) Thermal decomposition kinetics of light-weight composite $\mathrm{NaNH} 2-\mathrm{NaBH} 4$ hydrogen storage materials for fuel cells. Int J Hydrog Energy 37(17):12973-12979. https://doi.org/10.101 6/j.ijhydene.2012.05.069

47. Naktiyok J, Bayrakçeken H, Özer AK, Gülaboğlu MŞ (2017) Investigation of combustion kinetics of Umutbaca-lignite by thermal analysis technique. J Therm Anal Calorim 129(1):531-539. https://doi.org/10.1007/s10973-017-6149-z

48. Panic S, Kiss E, Boskovic G (2015) Thermal decomposition kinetics of carbon nanotubes-the application of model-fitting methods. React Kinet Mech Catal 115(1):93-104. https://doi.org/10.1007/s11144-014-0828-6

49. Xu T, Huang X (2010) Pyrolysis properties and kinetic model of an asphalt binder containing a flame retardant. J Appl Polym Sci 119(5):2661-2665. https://doi.org/10.1002/app.32841

50. Krauklis AE, Dreyer I (2018) A simplistic preliminary assessment of Ginstling-Brounstein model for solid spherical particles in the context of a diffusion-controlled synthesis. Open Chemistry 16(1):64-72. https://doi.org/10.1515/chem-2018-0011

51. Pang Y, Li Q (2016) A review on kinetic models and corresponding analysis methods for hydrogen storage materials. Int J Hydrog Energy 41(40):18072-18087. https://doi.org/10.1016/j.ijhydene.2016.08.018

52. Provis $\mathrm{J} \mathrm{L}$ (2016) On the use of the Jander equation in cement hydration modelling. RILEM Technical Letters 1:62-66. https://doi.org/10.21809/rilemtechlett.2016.13

53. Chou K-C, Hou X-M (2009) Kinetics of high-temperature oxidation of inorganic nonmetallic materials. J Am Ceram Soc 92(3):585-594. https://doi.org/10.1111/j.1551-2916.2008.02903.x

54. Lv W, LV X, LV X, Xiang J, Bai C, Song B (2018) Non-isothermal kinetic studies on the carbothermic reduction of Panzhihua ilmenite concentrate. Miner Process Ext Metall:1-9

\section{Publisher's Note}

Springer Nature remains neutral with regard to jurisdictional claims in published maps and institutional affiliations. 